suppression when used with ritonavir/lopinavir. HIV-infected children have a high incidence of chronic lung disease, which includes chronic obstructive respiratory disease. ${ }^{5}$ Given the large number of children who are prescribed ritonavircontaining antiretroviral regimens, many may be exposed to co-treatment with budesonide.

The daily dose of budesonide used in our cases varied from $200 \mu \mathrm{g}$ to $1200 \mu \mathrm{g}$. Adherence to medication was assessed by verbal report and medication demonstration by the caregiver. In case 2 the child was given medication by a trained nurse in a children's home and medication was boarded for us to review. Dosing of inhaled budesonide in children with obstructive lung disease is based on clinical response to treatment. Recommended dosing ranges from a low dose of $100-200 \mu \mathrm{g} / \mathrm{d}$ to higher doses of $>400 \mu \mathrm{g} / \mathrm{d}$. With the exception of case 1 these children were on moderate doses of budesonide only and in case 3 initially a low dose of fluticasone $(50 \mu \mathrm{g} / \mathrm{d})$. The fact that the children may have been overdosed cannot be entirely excluded. However, it appears that adrenal axis suppression can occur at standard recommended doses of budesonide and fluticasone when used concomitantly with ritonavir. This relationship requires further investigation.
The older nucleoside reverse transcriptase inhibitors (NRTIs) such as zidovudine and stavudine remain first-line therapy in our and other resource-limited settings. These drugs are associated with lipodystrophy and truncal obesity. It is important to consider Cushing's syndrome as a differential diagnosis and that the diagnosis of adrenal suppression is not missed. ${ }^{6}$

The combination of ritonavir and inhaled corticosteroids should be avoided. If co-therapy is necessary, careful physical examination and monitoring of adrenal axis function are essential.

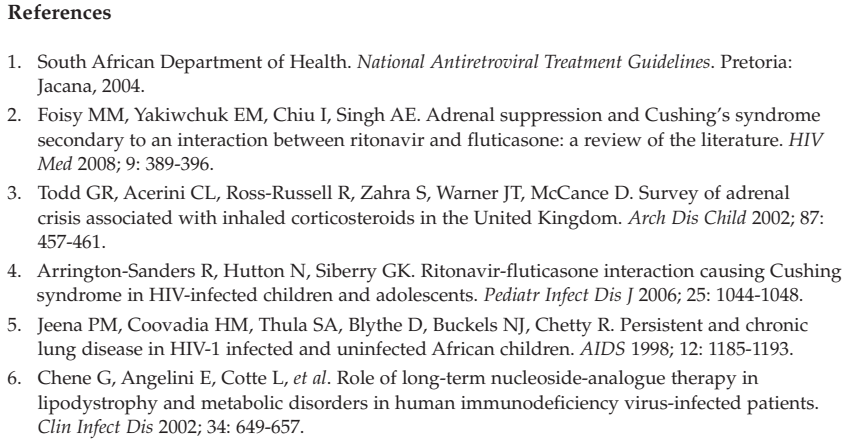

4. Arrington-Sanders R, Hutton N, Siberry GK. Ritonavir-fluticasone interaction causing Cushing syndrome in HIV-infected children and adolescents. Pediatr Infect Dis J 2006; 25: 1044-1048.

5. Jeena PM, Coovadia HM, Thula SA, Blythe D, Buckels NJ, Chetty R. Persistent and chronic lung disease in HIV-1 infected and uninfected African children. AIDS 1998; 12: 1185-1193.

6. Chene G, Angelini E, Cotte L, et al. Role of long-term nucleoside-analogue therapy in lipodystrophy and metabolic disorders in human immunodeficiency virus-infected patients. Clin Infect Dis 2002; 34: 649-657.

\title{
High prevalence of hookah smoking among secondary school students in a disadvantaged community in Johannesburg
}

\author{
A Combrink, N Irwin, G Laudin, K Naidoo, S Plagerson, A Mathee
}

To the Editor: Smoking of hookahs (also known as water-pipes) represents an emerging trend in tobacco use. ${ }^{1}$ Hookah smokers are at risk for the same diseases caused by cigarette smoking cancer, respiratory and heart diseases, and pregnancy-related complications. Globally, the highest rates occur in the North African and East Mediterranean regions and among young people in the USA and European countries. ${ }^{2}$ There has been little research on hookah smoking in southern Africa.

Faculty of Health Sciences, University of the Witwatersrand, Johannesburg A Combrink, $\mathrm{MB} \mathrm{ChB}$

N Irwin, MB ChB

G Laudin, MB ChB

K Naidoo, MB ChB

Environment and Health Research Unit, South African Medical Research Council, Johannesburg

S Plagerson, $\mathrm{PhD}$

Environment and Health Research Unit, South African Medical Research Council, Johannesburg, and Faculty of Health Sciences, University of Johannesburg A Mathee, $\mathrm{PhD}$

\section{Methods}

The Health, Environment and Development study, ${ }^{3}$ conducted by the South African Medical Research Council in five deprived areas of Johannesburg, observed surprisingly high rates of smoking in a community near the centre of Johannesburg. Anecdotal reports and direct observations pointed to a high frequency of hookah smoking as a possible explanation. Subsequently, undergraduate medical students of the University of the Witwatersrand were invited to conduct a health education workshop on the effects of hookah smoking in the secondary school serving this community. To inform the workshop, a baseline survey was conducted among the student population. All Grade 10 students were invited to participate. Approval to conduct the study was obtained from the school principal, and verbal consent was obtained from the individual students, following an explanation that the study was voluntary and anonymous and that the results would be used for research purposes only. The ages of participants $(N=202)$ in the four classes were from 14 - 20 years (mean 16.3 years). Three students elected not to participate. 


\section{Results}

The survey findings are summarised in Table I; $72 \%$ of respondents reported having used a tobacco product, including over $60 \%$ who said they had used or were using hookahs at the time of the study. A third of hookah users and a fifth of the entire sample reported daily use. Most respondents started smoking hookahs between the ages of 13 and 15 , while $21 \%$ had started when $\leq 12$ years old. The most common setting for smoking was social occasions (such as parties), with many also reporting home use. While the norm was to use tobacco in the hookah, significant numbers also reported using marijuana and/or alcohol-based products in combination with tobacco. Almost $10 \%$ of the total sample reported using marijuana in hookahs. The most common reason for smoking a hookah was the absence of alternative recreation ('nothing better to do'); other reasons were peer pressure, relaxation and addiction.

Among non-users, the vast majority said they would not consider smoking a hookah in the future; however, $39 \%$ had been subjected to pressure from peers to do so. Hookahs were perceived to be safer than cigarettes by most users, but as equally unsafe by the majority of non-users.

\section{Discussion}

The survey highlighted an alarmingly high rate of hookah use among the schoolchildren surveyed. Sixty per cent of study participants reported use of a hookah, including $20 \%$ who reported daily use, which is comparable with the rates observed among youths in settings where the use of hookahs is traditional. ${ }^{4}$ Our survey further highlighted the commencement of hookah use at a young age and the widespread use of tobacco in combination with substances such as alcohol and marijuana. In line with studies conducted elsewhere, the survey points to a widely held belief among users that hookah smoking is less harmful than other forms of smoking. ${ }^{5}$ Nevertheless, levels of awareness of the equally damaging effects to health of cigarettes and hookahs were higher among non-users.

Table I. Smoking patterns among secondary school students

\begin{tabular}{|c|c|c|c|c|c|c|}
\hline & \multicolumn{2}{|c|}{ Hookah users $(N=123)$} & \multicolumn{2}{|c|}{ Hookah non-users $(N=79)$} & \multicolumn{2}{|c|}{ Total $(N=202)$} \\
\hline & $\mathrm{N}$ & $\%$ & $\mathrm{~N}$ & $\%$ & $N$ & $\%$ \\
\hline \multicolumn{7}{|l|}{ Smokers (any tobacco product) } \\
\hline Cigarettes & & & & & 61 & 30.2 \\
\hline Hookah & & & & & 123 & 60.9 \\
\hline Other tobacco products & & & & & 15 & 7.4 \\
\hline Any tobacco product & & & & & 146 & 72.3 \\
\hline \multicolumn{7}{|l|}{ Frequency of hookah use } \\
\hline Tried only once or twice & 38 & 30.9 & & & 38 & 18.8 \\
\hline Weekly or less & 43 & 35.0 & & & 43 & 21.3 \\
\hline Daily & 41 & 33.3 & & & 41 & 20.3 \\
\hline \multicolumn{7}{|l|}{ Age of first use (years) } \\
\hline$<10$ & 5 & 4.1 & & & 5 & 2.5 \\
\hline $10-12$ & 21 & 17.1 & & & 21 & 10.4 \\
\hline $13-15$ & 62 & 50.4 & & & 62 & 30.7 \\
\hline $16-18$ & 34 & 27.6 & & & 34 & 16.8 \\
\hline \multicolumn{7}{|l|}{ Setting of use } \\
\hline At home & 47 & 38.2 & & & 47 & 23.3 \\
\hline At school & 3 & 2.4 & & & 3 & 1.5 \\
\hline Public places (e.g. cafes) & 6 & 4.9 & & & 6 & 3.0 \\
\hline At parties/with friends & 76 & 61.8 & & & 76 & 37.6 \\
\hline \multicolumn{7}{|l|}{ Substance in hookah } \\
\hline Tobacco only & 41 & 33.3 & & & 41 & 20.3 \\
\hline Tobacco and marijuana & 19 & 15.4 & & & 19 & 9.4 \\
\hline Tobacco and alcohol/spirits & 13 & 10.6 & & & 13 & 6.4 \\
\hline \multicolumn{7}{|l|}{ Reasons for smoking } \\
\hline Peer pressure & 17 & 13.8 & & & 17 & 8.4 \\
\hline 'Helps to relax' & 34 & 27.6 & & & 34 & 16.8 \\
\hline 'Nothing better to do' & 56 & 45.5 & & & 56 & 27.7 \\
\hline Addicted & 8 & 6.5 & & & 8 & 4.0 \\
\hline \multicolumn{7}{|l|}{ Openness to future use } \\
\hline Yes & & & 6 & 7.6 & 6 & 3.0 \\
\hline No & & & 73 & 92.4 & 73 & 36.1 \\
\hline \multicolumn{7}{|l|}{ Perceived pressure to smoke hookah } \\
\hline Yes & & & 31 & 39.2 & 31 & 15.3 \\
\hline No & & & 43 & 54.4 & 43 & 21.3 \\
\hline \multicolumn{7}{|l|}{ Hookah perceived as } \\
\hline Safer to smoke than cigarettes & 65 & 52.8 & 8 & 10.1 & 65 & 32.2 \\
\hline Less safe than cigarettes & 8 & 6.5 & 9 & 11.4 & 8 & 4.0 \\
\hline Equally unsafe as cigarettes & 52 & 42.3 & 51 & 64.6 & 52 & 25.7 \\
\hline
\end{tabular}


Though conducted on a small scale, our study plays an important role in bringing to light the disturbingly high prevalence of hookah smoking in one community, and points to an urgent need to conduct research on a nation-wide basis to determine the extent of hookah smoking in South Africa and the factors associated with its use. The reasons given by participants for commencing hookah smoking (e.g. boredom and a lack of recreational opportunities) imply a probable need for social and public health interventions that provide safer recreational alternatives to urban youth in Johannesburg and very likely elsewhere in South Africa.
References

1. Maziak W, Ward D, Afifi S, Soweid R, Eissenberg T. Tobacco smoking using a waterpipe: a re-emerging strain in a global epidemic. Tobacco Control 2004; 13(4): 327-333,

WHO. Waterpipe Tobacco Smoking: Health EffectsResearch Needs and Recommended Actions by Regulators. Geneva: World Health Organization, 2005.

3. Mathee A. Indicators of Health, Environment and Development: A Longitudinal Study in Johannesburg 2006-2008. Johannesburg: World Health Organization Collaborating Centre for Urban Health, 2009.

4. Afifi R, Yeretzian J, Rouhana A, Nehlawi M, Mack A. Neighbourhood influences on narghile smoking among youth in Beirut. Eur J Publ Health 2009; 2 Nov [epub ahead of print].

5. Roskin J, Aveyard P. Canadian and English students' beliefs about waterpipe smoking: a qualitative study. BMC Publ Health 2009; 10(9): 10.

Accepted 24 December 2009

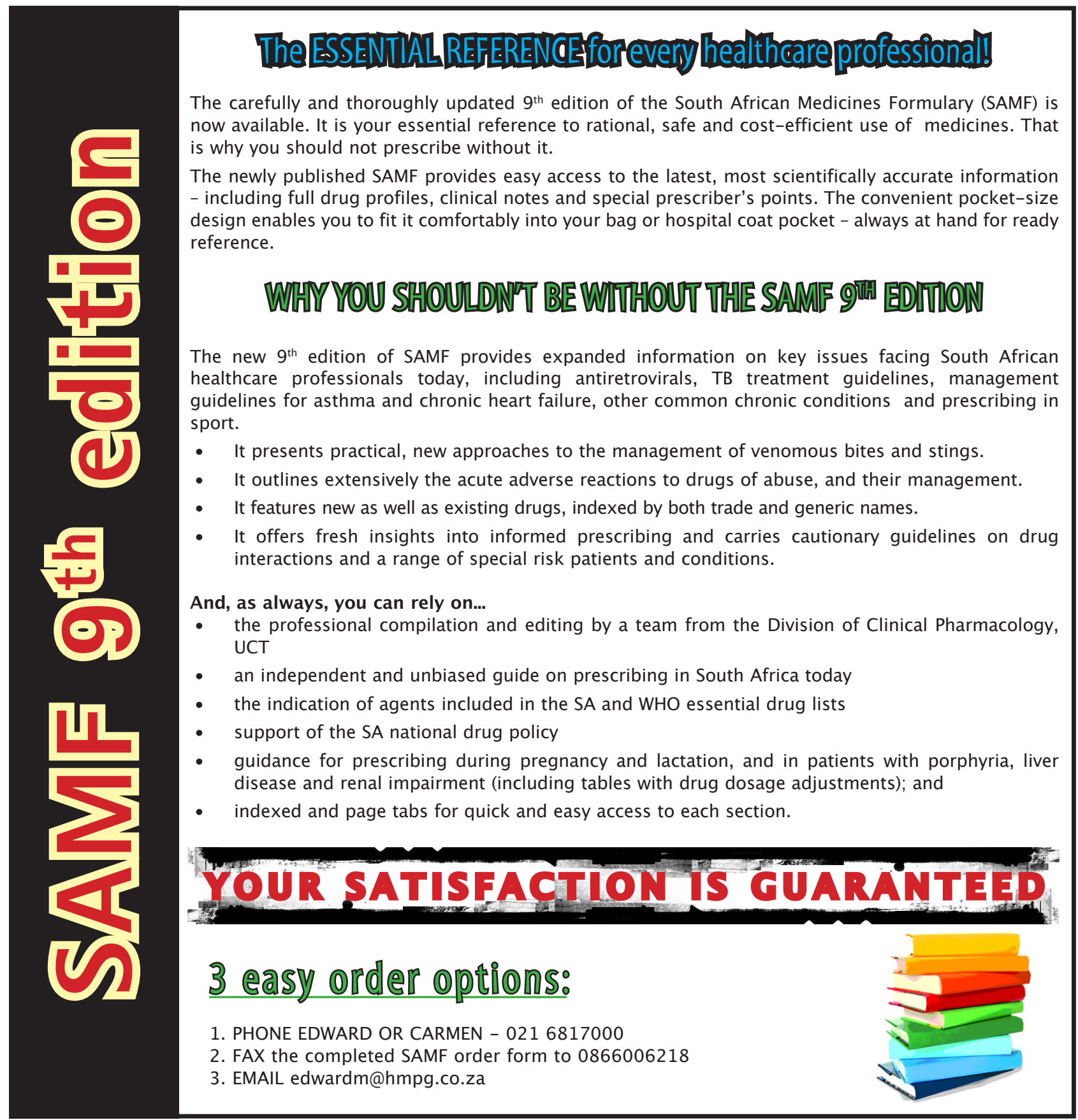

